\title{
QUANDO O SUJEITO (NÃO) FALHA EM LÍNGUA ESTRANGEIRA: A PRESENÇA DO LAPSO COMO MANIFESTAÇÃO CONSTITUTIVA DO SUJEITO
}

\author{
CHRISTIANO TITONELI SANTANA ${ }^{1}$
}

\begin{abstract}
Programa de Pós-Graduação em Estudos de Linguagem
Instituto de Letras da UFF - Rua Professor Marcos Waldemar de Freitas Reis, s/no. Campus do Gragoatá, Bloco C, sala 518. CEP: 24210-201, Niterói - RJ

christiano.titoneli@gmail.com, christiano.santana@ifnmg.edu.br
\end{abstract}

\begin{abstract}
Resumo. Neste estudo, como excerto de nossa pesquisa mais ampliada, debruçamo-nos na noção de lapso (MAIA, 2006) com relação ao sujeito entre línguas - materna e estrangeira. Tal estudo dá-se a partir de produções textuais escritas por alunos universitários em Letras com habilitação em língua inglesa, em uma universidade pública do estado do Rio de Janeiro. À luz da Análise do Discurso de linha francesa, conforme desenvolvida por Pêcheux (2010), buscaremos estudar a materialidade produzida pelos sujeito-alunos em forma de possíveis lapsos. Nosso intento é, com base nos recortes do corpus, pôr em relevo os tipos de lapsos mais comuns, assim como classificá-los e analisá-los como tensão constitutiva provocada pelo encontro da língua materna com a estrangeira. Poderemos, deste modo, problematizar a perspectiva que considera a relação do lapso com o sujeito em língua estrangeira como erro ou desvio, e não como um espaço para a materialidade e produção de um sujeito que marca sua inscrição na língua outra.
\end{abstract}

Palavras-chave: Análise do Discurso; sujeito; lapsos; língua estrangeira; língua materna.

\begin{abstract}
In this study, as excerpt of our broader research, we take a deep look at the notion of lapses (MAIA, 2006) with respect to the subject between two languages - mother tongue and foreign language. This study comes from textual productions written by university students in Liberal Arts, majored in English language at a public university in the state of Rio de Janeiro. In light of the French Discourse Analysis, as developed by Pêcheux (2010), we will study the materiality produced by student-subjects in the form of possible lapses. Our intent is, based on the excerpts of the corpus, to highlight the most common types of lapses, and classify them and analyze them as constitutive tension caused by the relationship of the mother tongue with the foreign one. We may therefore question the perspective that considers the relationship between the lapses and the subject in a foreign language as an error or
\end{abstract}

\footnotetext{
${ }^{1}$ Doutorando em Estudos de Linguagem na Universidade Federal Fluminense; professor de Língua Inglesa do Instituto Federal do Norte de Minas Gerais. http://lattes.cnpq.br/2442786998285426.
} 
deviation, not as a space for the materiality and production of a subject that is inscribed in the other language.

Keywords: Discourse Analysis; subject; lapses, foreign language, mother tongue.

\section{Considerações iniciais}

Este estudo, oriundo de uma pesquisa mais expandida, trata de investigar a noção de lapsos produzidos pelo sujeito entre línguas - língua materna (LM) e língua estrangeira (LE) - com foco na produção textual em LE. Cabe ressaltar que este trabalho filia-se ao quadro teórico da Análise do Discurso de linha francesa, fundada por Pêcheux (1997/2010), que se desenvolveu no Brasil por meio dos trabalhos de Orlandi (2013). Neste recorte de nossa pesquisa, em especial, analisamos as possíveis marcas do sujeito por meio de lapsos como expressão material da tensão constitutiva de um sujeito entre línguas no processo de escrita.

As produções textuais foram realizadas nas turmas do curso de graduação em Letras (Inglês/Português) nas disciplinas introdutórias em tradução, em uma universidade pública do estado do Rio de Janeiro. Os alunos foram solicitados a ler o conto Old Man at the Bridge, de autoria de Hemingway (1963), e a produzir um texto em língua inglesa sobre a representação do idoso no conto levando em consideração o cenário da história. Além disso, foi explicado aos alunos para que escrevessem o texto em prosa sem um limite determinado de linhas. Vale acrescentar que os alunos tiveram apenas uma explicação de que se tratava de um conto, que o vocabulário e a linguagem remetiam ao inglês do início do século XX. Foi explicado que a pesquisa era sobre produção textual, porém em uma perspectiva discursiva. Isto é, não seriam avaliados os então chamados potenciais desvios ou interferências. No contato com os alunos, explicamos ainda que nossa preocupação era na visada discursiva. Os alunos foram conduzidos a ler sem se ater a um vocabulário ou outro que se figurasse como obstáculo para o entendimento, foram estimulados a ler o texto em sua forma global.

Nosso objetivo é pensar a língua estrangeira (LE) à luz da AD, uma vez que, em termos de pesquisa, esse encontro ainda apresenta-se reduzido, embora haja trabalhos de referência e relevância na área, como os de Celada (2008), De Nardi (2002; 2007), Serrani-Infante (1998), Payer e Celada (2011), entre outros. Mobilizar a discussão em torno do sujeito em LE, do lapso e da produção textual torna-se importante uma vez que os estudos atuais voltados à LE dialogam com o campo da linguística aplicada. Pensamos, então, a produção textual e o sujeito com base em uma visada discursiva, em especial pecheutiana. Nesta perspectiva, podemos compreender a produção textual em LE, levando em conta um sujeito atravessado pelo inconsciente, que, sem se dar conta, produz certos lapsos denominados, normalmente, como falhas, estruturas da LM e, por assim dizer, considerados como erros ou interferências pela maior parte das ciências da linguagem. 
O sujeito entre línguas pode estar (ou não) fortemente filiado à LE, mas não deixa de marcar na produção de sentidos aquilo que é constitutivamente dele: os lapsos. Em particular, abordamos essa questão ligada à escrita na produção textual em LE, uma vez que em nosso corpus foram marcados lapsos de sujeitos-aluno com diferentes perfis: uns extremamente inscritos na LE e outros que não se implicam no texto, isto é, que na produção textual imprimiam fragmentações e rupturas no fio discursivo. Para pensar os lapsos, recorremos a essa noção trabalhada por Maia (2006) para estudá-los na produção textual em LE. Para a maior parte dos estudos voltados à LE, os lapsos são considerados erros, desvios, interferência da LM na LE - são rotulados como o lixo da linguagem. Da perspectiva discursiva que assumimos, buscamos tratá-los como um processo natural e constitutivo da relação entre o sujeito e a língua. Pois, o olhar pragmático para a língua tende a higienizar esses traços ao pensar que causam rupturas; entretanto, nosso intento é trabalhar nessas e por essas estruturas.

Com enfoque, a princípio, na questão da inscrição do sujeito na língua outra, é importante destacar que estar inscrito em uma LE é um processo contínuo e de nunca acabar, porque o sujeito em LE é um sujeito entre línguas. Estar entre línguas é condição fundadora do sujeito em LE, porque como nos diz Revuz (1998), a LM sempre está presente no funcionamento da LE, porque os primeiros olhares, as primeiras perspectivas e o modo de conhecer o mundo foram desenhados e configurados pela LM na condição ainda de infans. Ao revistarmos Orlandi (2013) e pensarmos na passagem do indivíduo para sua forma-sujeito caracterizada pela forma bio-psico-social, atravessado pelo inconsciente, acabamos por ter mais um caminho de possibilidade para entender que tal passagem dá-se pela existência dessa LM. Estar entre línguas na posição de sujeito em LE é condição constitutiva do sujeito, não há desprendimento. Por um lado, quanto mais o sujeito envolve-se na LE, deixa-se afetar pelos dizeres dessa outra língua e inscrever-se em filiações de sentidos dessa LE, mais ainda, por outro lado, na materialidade linguística a presença da LM vai se apagando. Entretanto, a LM sempre estará ali forçando o seu lugar de primeira língua, podendo ora romper no nível linguístico-enunciativo, ora no nível discursivo, em que os dizeres replicados vêm da primeira língua.

Ao considerar o abalo, de maneira constitutiva, ocasionado pelo encontro entre duas línguas (LM e LE), Serrani-Infante (2000, p. 118) reforça que:

a aprendizagem de segunda(s) língua(s) solicita os fundamentos da estruturação psíquica do sujeito e o que é instrumento e matéria dessa estruturação: a língua materna. [...] Mas essa estrutura - por ser singular - não deixa de estar inscrita numa rede de memórias discursivas, nas quais posições particulares resultam de relações contraditórias de poder e sentido, num determinado contexto sócio-histórico. [...] na enunciação em segundas línguas trata-se de muito mais do que uma questão de formas linguísticas e funções. Trata-se de sujeito e sua singularidade contraditória posta em questão pelo encontro com segundas-línguas.

Levando em consideração a produção textual e a relação do sujeito em implicarse (in)conscientemente na língua outra de modo a construir sentidos, temos como caminho a noção de um sujeito entre línguas. Isto significa que o sujeito se implicando e 
se inscrevendo continuamente na LE pelo processo de aprendizagem, a LM, por sua vez, faz-se presente - é o está-ali da constituição do sujeito entre línguas. Quanto à noção do sujeito e a LE na aprendizagem, Serrani-Infante (1998, p. 147) nos diz:

Entendemos que o sujeito "aprende" significativamente uma segunda língua quando, pronto para a experiência do próprio estranhamento, se inscreve, por processos identificatórios, em discursos, mais especificamente em formações discursivas da segunda língua-cultura.

Isso rompe, por assim dizer, com a concepção de aquisição da língua, qual seja, a crença de que para falar uma LE é necessário memorizar palavras e estruturas, como se fosse um jogo apenas de (re)combinação. Isso é explorado por Celada (2008), quando aponta que falar de LE é também pensar o sujeito em relação à língua como indissociáveis. Este ponto de ancoragem para a $\mathrm{AD}$ a respeito da aprendizagem da $\mathrm{LE}$ torna-se enriquecedor quando pensamos que para estar na língua outra é preciso engajarse, implicar-se e inscrever-se nos dizeres dessa língua do outro, é deixar, sem se aperceber muitas vezes, ser capturado por dizeres que ecoam da LE, antes desconhecidos e remotos.

\section{Pensando o lapso como marca da materialidade do sujeito em LE}

Para mobilizarmos a noção de lapso aplicada à produção textual em LE, recorremos ao trabalho de Maia (2006). A autora trabalha a questão do lapso com foco em 120 relatórios de estudos de caso relacionados a adolescentes infratores da lei dentro de uma instituição subordinada ao Departamento Geral das Ações Sócio-Educativas (DEGASE). Tais relatórios eram escritos por técnicos tendo como fonte as entrevistas com diferentes adolescentes e, posteriormente, eram enviados ao juiz para que ele decidisse quanto à permanência ou não no regime de internação naquela instituição. Ao analisar tais relatórios, Maia (2006) buscou estudar os lapsos e como se manifestava o olhar dos técnicos no processo de escrita a partir do relato dos adolescentes. Podemos a título de análise visitar um trecho de um relato trabalhado por Maia (2006, p. 184), em que o relatório A00 diz: "Diz ser esta a sua primeira apreensão". Nesse trecho, a autora discute que no relatório o técnico, no processo de escrita, faz uso do discurso indireto livre. Isso levanta a questão de que "os lugares dos locutores não ficam tão bem definidos" (op.cit., p. 183).

Ao articular sua discussão sobre o lapso a partir desse trecho, a autora argumenta que a expressão "primeira apreensão" apresenta um traço de lapso, uma vez que "aponta para outras possibilidades de significação 'receio', 'preocupação' e 'cisma"” (ibidem). Ou melhor, segundo a autora, há dois sentidos possíveis de circular, isto é, o garoto no relato foi apreendido fisicamente e levado ao confinamento, e outro sentido como "momento de preocupação, dando espaço a uma manifestação subjetiva do menino" (Ibidem.). Há, então, a ideia de lapso aqui como possibilidade de outros sentidos, e não apenas aquele que o técnico busca traçar - o sentido se escapa. Além disso, o técnico se autoriza a colher informações e linearizá-las com a sua voz, de algum modo intervindo no sentido também. A noção do lapso para a autora significa, portanto, transformar um enunciado em outro (in)conscientemente. 
Seguimos nesta investigação com a mesma concepção de lapso empregado por Maia (2006, p. 161), quando diz que:

[...] lapsos dizem diretamente sobre o sujeito, isto é, coloca o sujeito em cena e sob investigação, rompendo com a própria posição ideológica da ciência, em geral, e da ciência linguística, em particular, que busca acima de tudo neutralizar o sujeito.

Em consideração ao lapso na produção textual em LE, há o imaginário de que o erro, o desvio, o engano são pontos que não devem ser levados em consideração. Tal perspectiva é reforçada pelas principais linhas teóricas ligadas ao estudo de LE, como no caso da Linguística Aplicada. Segundo Aiub (2014, p. 61), "A relação, portanto, entre línguas, vista sob a ótica da LA [Linguística Aplicada], é percebida, mas é trabalhada pelo viés do erro. O aprendiz erra quando ele faz relações entre as línguas que estão lhe constituindo: materna e estrangeira". Mas a AD, por sua vez, vê no lapso a pista, a marca de um sujeito entre línguas que não se deixa vencer, e busca inscrever-se na língua outra (in)conscientemente. Tais lapsos na LE podem configurar-se, segundo nosso corpus, da seguinte forma: i) por meio da grafia (quando as palavras entre as duas línguas mantêm algum grau de similaridade na escrita e no sentido); ii) caso de (im)possibilidade da língua (quando o sujeito escreve na LE uma palavra inexistente na língua-alvo.

Os lapsos não têm relação, para a $\mathrm{AD}$, com erro, relacionam-se àquilo que é naturalmente do sujeito: a busca constitutiva do sujeito pela completude do sentido, de dar conta de todos os sentidos. E, durante o percurso, o sujeito tropeça, porque o tropeçar faz parte de sua constituição, é um "Sujeito à falha, ao jogo, ao acaso, e também à regra, ao saber, à necessidade. Assim o homem (se) significa" (ORLANDI, 2013, p. 53). Como diz Maia (2006, p. 163), os lapsos deixam "transparecer um não dito, um sentido que escapa à expectativa"; por isso, o lapso é um caminho para pensarmos essa relação do sujeito entre línguas, porque pelos lapsos se imprimem a vontade, o desejo, o querer-estar em uma língua outra e ser o outro. Lapso materializa-se como a luta, a materialização do sujeito de ser ilusoriamente aquele da língua-alvo. O lapso é da constituição do sujeito independentemente de qual língua seja.

Buscar entender o lapso em relação à produção de sentidos de um sujeito entre línguas é, de alguma forma, subverter-se ao que os estudos sobre metodologias e abordagens de LE intentam trabalhar. Como Revuz (1998, p. 215) nos alerta sobre o trabalho entre línguas, "as didáticas de línguas estrangeiras não têm se interessado nesse confronto e não têm procurado analisá-lo nem trabalhá-lo". Mas colocamo-nos nesse trabalho inicial de pensar um sujeito entre línguas em face a uma produção textual, em que dele se espera, constitutivamente, crer de forma ilusória, como traço constitutivo do sujeito, que ao escrever não produzirá erros, e estará plenamente do lado da LE. Entretanto, deixará, em algum momento, impresso o lapso - porque isto é natural do sujeito, porque ele sempre tentará dizer o mesmo de outro modo, e nesse jogo haverá deslizes de sentido, rupturas, deslocamentos e lapsos.

Estudemos, então, algumas sequências discursivas (SD) a partir de certas produções textuais que marcam o lapso como resultado do processo de escrita de um sujeito entre línguas. 
(SD 1) The old man was always sitting near a bridge, sadly, aperantly, with no hope and no expectation.

(SD 2) The first paragraph of the text shows that the old man keeped his self static, although the scenario was in a absolutely movement.

(SD 3) Because the animals were just an apologise for this man to forget who he doesn't has anymore: his family, his animals, his personality, his life.

(SD 4) An old man lost in the middle of a caotic place that moves forward, going right after the caos scenario that moves.

As SDs de 1 a 4 apresentam uma regularidade no que diz respeito a inadequações ortográficas, denominadas pelos estudos da linguística aplicada como erros, desvios e interferências. $\mathrm{O}$ ensino de LE pelo viés da linguística aplicada tende ainda a pensar o erro como um entrave constante, como se a LM fosse o eixo responsável pelos insucessos do sujeito na inscrição em LE. Precisamos perceber que, na visada discursiva, o erro não denota barragem, limite e entrave, mas sim a luta de um sujeito que deseja estar na LE. Em outras palavras, o sujeito, para produzir sentidos, precisa antecipar, sentir-se na LE ilusoriamente comunicando suas ideias de forma plena. Entretanto, é nesse empreendimento na língua outra que o sujeito deixa escapulir, sair, exceder aquilo que natural, original e constitutivamente faz parte de si: a LM. Creditar à LM um lugar negativo, improdutivo é esquecer que o sujeito pode estar inscrito de forma implicada na LE, ser capaz de posicionar-se como sujeito-autor e produzir sentidos ao sentir-se no lugar, imaginariamente, de um nativo dessa língua outra. Porém, se ele o faz é justamente porque há uma língua que o constitui primeiro e o possibilitou constitutivamente a embrenhar-se em outro real possível, isto é, o da LE. A LE é a continuação da LM, pois o sujeito estará constituído a todo instante nesse lugar de flexibilização e de produção de sentidos entre línguas.

Temos exemplos desse funcionamento contínuo entre LM e LE nas sequências 1, 3 e 4, em que se vê, respectivamente:

(SD 1) "The old man was always sitting near a bridge, sadly, aperantly, with no hope and no expectation";

(SD 3) "Because the animals were just an apologise for this man to forget who he doesn't has anymore";

(SD 4) "An old man lost in the middle of a caotic place that moves forward, going right after the caos scenario that moves".

De cada SD, temos "aperantly", "doesn't has" e "caotic" considerados em algumas abordagens, que não consideram a língua em sua historicidade, como erros e desvios. Orlandi (2013, p. 25) nos diz que "a linguagem é linguagem porque faz sentido. E a linguagem só faz sentido porque se inscreve na história". Essas SDs denunciam não um erro, mas um lapso de um sujeito entre línguas que busca estar na LE, mas em quem incide o movimento mais forte da LM. Ao pensarmos nas SDs 1 e 4, temos o tão conhecido erro ortográfico, em que se marca um sujeito ainda tentando escrever na LE, enquanto a forma ortográfica na LM se faz presente de forma latente. A essa marca 
chamamos de lapso na $\mathrm{AD}$, porque o sujeito quando quer dizer algo, ele diz a partir de uma dada posição.

Partindo do trabalho desenvolvido por Maia (2006) quando pensa a escrita permeada por lapsos, conforme apresentamos e abordamos anteriormente, compreendemos que "As formas de lapso de escrita podem ser variadas: há casos de repetição ou esquecimento de palavras, de distorção de nomes, de supostos erros tipográficos ou ortográficos" (op.cit., p. 162). Aplicamos esse conceito ao sujeito em LE porque entendemos que o lapso é constitutivo do sujeito, independentemente de qual língua ele estiver produzindo sentidos. Se ele tropeça, isso forma uma marca de que a relação da língua com a história produz um sentido na LM diferente da LE, isso mostra que a historicidade não é transferida. A historicidade vem a partir da constituição da língua com o sujeito. Portanto, se o sujeito-aluno escreve "aperantly" em vez de "apparentely"; "doesn't has" no lugar de "doesn't have"; ou caotic e caos" em vez de "chaotic", marca um sujeito que ainda mantém (in)conscientemente essa relação mais latente com a historicidade da LM. O lapso na LE, assim como o lapso na escrita como trabalhado por Maia (2006, p. 163), "pode ser encarado como uma ideia recalcada ou silenciada do que retorna, enviesada, por causa de uma censura de ordem consciente". Isso cai na questão do policiamento e na vigilância quanto à ortografia na LE que fazem o sujeito-aluno de língua inglesa (futuro professor) ser compelido a não errar, porque dele é esperado o certo, a completude, a certeza para todas as dúvidas.

Isso abre um caminho para pensar que apontar os lapsos na língua outra como um erro é ignorar que o sujeito, além de ser atravessado por uma ordem inconsciente, está em todo momento lutando - (in)conscientemente - para se estabelecer ilusoriamente na LE. Entretanto, o sujeito luta para dizer seja em qual língua for e a todo instante, porque dizer é escolher, deixar de dizer e (não) dizer. Pensar a LE como um caminho, pelo qual há barragem de sentido porque o sujeito está aprendendo uma língua nova, é cair na ilusão pragmática de que o sujeito vê-se impedido de falar somente quando está na LE, e não na LM também. Produzir sentidos na LE ou LM é jogar com e no campo das possibilidades de sentido. Os lapsos, quando olhados longe do sentido de negatividade, são materialidade para compreendermos como o sujeito tende a produzir sentidos em um dado momento histórico. Tais lapsos fazem parte da produção de sentido desses sujeitos-aluno, pois conseguem expressar seus pontos de vista, especialmente quando em SD 3, por exemplo, aponta que os animais foram apenas uma desculpa para o homem não pensar na própria família. Isso nos convoca a perceber que o lapso imprime rastros de um sujeito que se sente à vontade em expressar-se na língua outra, põe o seu dizer em circulação na LE, porém, em seu dizer a LM ainda incide no nível da materialidade linguística. Isso mostra um sujeito que à medida que se implica na LE, e se reforça um imaginário da própria LM da qual a relação pensamento-linguagem-mundo é transparente.

\section{Consideremos a SD 2 a seguir,}

(SD 2) "The first paragraph of the text shows that the old man keeped".

Vemos na SD 3, "old man keeped his self static", que "keeped" é considerado, conforme a gramática normativa de língua inglesa, um erro de conjugação verbal, uma vez que esta forma não está regularizada na língua inglesa. Tal lapso é cometido por 
crianças quando estão se inscrevendo na língua inglesa e trocam a forma padrão do verbo "kept" por "keeped". Casos semelhantes acontecem em português, quando a criança troca o verbo "eu fiz" na primeira pessoa do singular pela forma não padrão "eu fazi". Isso demonstra que o sujeito, embora se expresse escrevendo na LE de forma a constituir sentidos, deixa escapar por meio de lapsos o seu senso de vigilância e sua preocupação em não errar e de ter todos os tempos verbais corretamente memorizados. É um desejo que permanece tão recalcado que se irrompe na materialidade linguística. A princípio, causa estranhamento, mas não embaralha, estilhaça ou compromete o sujeito-aluno de se expressar. Como diz Bertoldo (2003, p. 102),

O desejo pelas línguas estrangeiras não advém do desejo de aprendê-las enquanto sistemas estruturados gramaticalmente, mas sim do desejo de adentrar e aderir a uma outra discursividade em que o sujeito busca um lugar onde vê satisfeita a sua ânsia de poder escolher uma ordem na qual possa exprimir.

Em todas estas SDs de 1 a 4, percebemos que o sujeito não se deixa vencer pelos embates que a língua outra impõe. Como diz Pêcheux (2010, p. 281), "não há dominação sem resistência". Isto é, ser dominado por um outro recorte de real (REVUZ, 1998) é (in)conscientemente se indagar, se revoltar, pois isto é natural do sujeito. Mas é nessa relação de dominação que o sujeito passa a buscar querer se apagar da LM para dizer da melhor forma, ainda que ilusoriamente, em LE. A dominação, aqui, não implica um sentido imperialista sobre a língua - é constitutiva da língua, independentemente de qual seja, essa relação de resistência do e com o sujeito. No caso dessas SDs, os sujeitos-aluno deixam marcas de lapso, mas produzem sentidos nessas passagens da produção textual. Marcam um fio discursivo por meio de sentidos possíveis do conto e os perspectivam com o saber que trazem na língua. Isso mostra que produzir sentido é possível na língua outra, apesar de ou por causa dos lapsos, que, por sua vez, precisam ser levados em conta, já que a subjetividade do sujeito está posta a todo instante e constantemente na produção de sentidos. Entendemos, assim, que lapsos são também marcas para detectar a latência da inscrição do sujeito entre línguas e perceber suas lacunas, suas faltas na língua outra um funcionamento tão natural e constitutivo quanto a sua ocorrência na LM.

\section{Considerações finais}

Apresentar este recorte de nossa investigação já, de certo modo, configura uma subversão às práticas de ensino em LE atuais, mas também é uma tentativa de pensar o sujeito entre línguas que falha, avança, estagna, repete, não diz, retrai, se esconde, mas que não deixa de ser menos sujeito por isso. Porque todos esses aspectos são partes constitutivas do sujeito, e este estudo leva em conta a luta e o embate do sujeito para construir sentidos discursivamente, mas com um olhar para a materialidade linguística. Buscar repensar a produção textual estabelecendo um diálogo com os lapsos como um aspecto importante e analisável, enquanto a maior parte da ciência da linguagem entende como resto e lixo, é pôr em prática o que a nossa relação com a $\mathrm{AD}$ vem nos ensinando: entender o sujeito como inacabado porque a língua em si é inacabada. Daí os sentidos poderem ser outros, porque não há univocidade de sentido. Produzir um texto é 
imaginariamente achar-se o dono das palavras e controlador dos sentidos, mas tornar-se responsável pelos sentidos que ilusoriamente contorna - porque aí há o engajamento do sujeito em dizer de um modo, e não de outro.

Escrever em LE, ou em LM, impõe ao sujeito não apenas a caneta e o papel (simbolizados em diferentes formas), é preciso dele esforço, força, não no sentido físico, mas discursivamente marcar e produzir sentidos. Estar em LE é uma relação de constante imbricação e envolvimento, é, por vezes, imaginar-se lá na outra língua. Significa também esquecer-se da LM, mas ela não se desprende ou descola do sujeito, porque ela sempre está na sua formação, pois foi o dela seu primeiro olhar para o mundo. Não se mede o quanto se está implicado em uma LE; pelo contrário, para a $\mathrm{AD}$, inscreve-se em um processo de nunca acabar. É na flexibilização, no vaivém entre línguas que o sujeito se permite, se deixa estar (in)conscientemente na autonomia ilusória.

Como vimos neste estudo, quanto mais o sujeito inscreve-se e ousa estar imaginariamente na língua outra, mais ele se implica de forma a se sentir pertencente à LE. Isso abre portas para que o sujeito desenvolva a crença da autonomia e da liberdade na LE, assim como ele já a tem em sua LM. E todo esforço de se dizer na LE não é de forma consciente, o inconsciente também trabalha a todo instante como parte da constituição do sujeito. Isso indica que o sujeito se põe a dizer algo em LE em meio a tensões entre LM e LE que são mais evidentes ou menos a depender de quanto o sujeito estiver inscrito na língua. Assim como na LM, quanto mais sentir-se no controle e na ordem da reformulação dos sentidos na LE, mais poderá produzir marcas de lapsos de diferentes naturezas, que evidenciarão o envolvimento do sujeito nessa língua outra.

\section{Referências bibliográficas}

AIUB, G.F. Sujeito entre línguas materna e estrangeira: lugar de interferências, historicidades e reverberações. Curitiba: Apris, 2014.

BERTOLDO, E.S. O contato-confronto com uma língua estrangeira: a subjetividade do sujeito bilíngue. Em: CORACINI, M.J.F. (Org.). Identidade e discurso: (des)construindo subjetividades. Campinas: Editora da Unicamp; Chapecó: Argos Editora Universitária, 2003. p. 83-118.

CELADA, M.T. O que quer, o que pode uma língua? Língua estrangeira, memória discursiva, subjetividade. Letras, 37, v. 18, n. 2, 145-168, 2008.

DE NARDI, F.S. Outros dizeres para o ensino de Segunda língua: um lugar para a tomada da palavra no terreno da opacidade e do real. Dissertação. Mestrado em Letras. Universidade Federal do Rio Grande do Sul, Porto Alegre, 2002.

HEMINGWAY, E. Old man at the bridge. In: FULLER, E. (Ed.). Adventures in American Literature. New York: HBW, 1963. 
MAIA, M.C.G. Instâncias de subjetivação em relatórios sobre adolescentes infratores. Tese. Doutorado em Estudos Linguísticos, Instituto de Letras, Universidade Federal Fluminense, Niterói, 2006.

ORLANDI, E. Análise de discurso: princípios e procedimentos. 11ª . ed. Campinas: Pontes, 2013.

PAYER, M.O.; CELADA, M.T. Relação sujeito/língua(s) - materna, nacional, estrangeira. Em: SILVEIRA, E.M. As bordas da linguagem. Uberlândia: EDUFU, 2011.

PÊCHEUX, M. Semântica e Discurso: uma crítica à afirmação do óbvio. Campinas: Editora Unicamp, 2010.

Por uma análise automática do discurso: uma introdução à obra de Pêcheux. Em: GADET, F. \& HAK, T. Trad. Bras. Campinas: Editora da Unicamp, 1997.

REVUZ, C. A língua estrangeira entre o desejo de um outro lugar e o risco do exílio. Em: Língua(gem) e identidade - elementos para uma discussão no campo aplicado. $2^{\mathrm{a}}$. ed. Campinas: Mercado de Letras, 2002. p. 213-230.

SERRANI-INFANTE, S. Identidade e segundas línguas. Em: SIGNORINI, I. (Org.). Língua(gem) e identidade. São Paulo: Mercado de Letras, 1998. p.231-264.

Singularidade discursiva na enunciação em segundas línguas. Em: LEITE, N.V.A. (Org.). A singularidade como questão [Cadernos de Estudos Linguísticos, 38], Campinas, IEL, UNICAMP, jan-jun 2000.

Artigo recebido em: outubro de 2016.

Aprovado e revisado em: janeiro de 2016.

Publicado em: abril de 2017.

\section{Para citar este texto:}

SANTANA, Christiano Titoneli. Quando o sujeito (não) falha em língua estrangeira: a presença do lapso como manifestação constitutiva do sujeito. Entremeios [Revista de Estudos do Discurso, on-line], Seção Temática - Língua(gem) e Ensino, Programa de Pós-Graduação em Ciências da Linguagem (PPGCL), Universidade do Vale do Sapucaí (UNIVÁS), Pouso Alegre (MG), vol. 14, p. 233-242, jan. - jun. 2017.

DOI: http://dx.doi.org/10.20337/ISSN2179-3514revistaENTREMEIOSvol14pagina233a242 